\title{
Student-Generated Videos for Thermodynamics Teaching and Learning
}

\author{
Dr. James P Abulencia, Manhattan College \\ Dr. Margot A Vigeant, Bucknell University
}

Margot Vigeant is a professor of chemical engineering and an associate dean of engineering at Bucknell University. She earned her B.S. in chemical engineering from Cornell University, and her M.S. and $\mathrm{Ph} . \mathrm{D}$., also in chemical engineering, from the University of Virginia. Her primary research focus is on engineering pedagogy at the undergraduate level. She is particularly interested in the teaching and learning of concepts related to thermodynamics. She is also interested in active, collaborative, and problem-based learning, and in the ways hands-on activities and technology in general and games in particular can be used to improve student engagement.

\section{Dr. David L. Silverstein P.E., University of Kentucky}

David L. Silverstein is a Professor of Chemical Engineering at the University of Kentucky. He is also the Director of the College of Engineering's Extended Campus Programs in Paducah, Kentucky, where he has taught for 15 years. His PhD and MS studies in ChE were completed at Vanderbilt University, and his BSChE at the University of Alabama. Silverstein's research interests include conceptual learning tools and training, and he has particular interests in faculty development. He is the recipient of several ASEE awards, including the Fahein award for young faculty teaching and educational scholarship, the Corcoran award for best article in the journal Chemical Engineering Education (twice), and the Martin award for best paper in the ChE Division at the ASEE Annual Meeting. 


\title{
Student-Generated Videos for Thermodynamics Teaching and Learning
}

\begin{abstract}
Current college students are accustomed to documenting and sharing their experiences through text, photo, and video, thanks to the ready availability of all of these through personal portable devices. The democratization of video production and access has lead to the possibility to both teach and learn with video as never before. This work seeks to capitalize on student expectations and the current technological environment to bring the benefits of both teaching and learning with video into core technical undergraduate engineering courses. Specifically, in this work we ask student teams to create short, targeted, easy to understand videos about concepts in thermodynamics, and then invite them to watch the faculty-vetted library of videos developed by their peers at their own and two collaborating institutions. We are studying changes in students' conceptual learning as a result of participation in this program, and are building a repository of accurate, engaging videos for thermodynamics learning that will ultimately be shared with other instructors and the public.
\end{abstract}

\section{Background and Methods}

This work is a component of a broader study between three institutions that seek to evaluate the effect of video generation and viewing on student understanding of several thermodynamics concepts: 1) Entropy and the Second Law, 2) Reversibility, 3) Steady State vs Equilibrium, 4) Internal Energy vs Enthalpy, and 5) Reaction Rate vs Reaction Equilibrium (Abulencia - 2013; Abulencia - 2014).

The focus of this paper is to examine the effect of students both creating and viewing peer-generated videos (21 total) of the aforementioned topics. The viewing assignment coincided with the time that particular topic was being taught in lecture and was part of regular homework. The video creation project was assigned to teams of 3-4 students as a significant assignment spanning the last 4-5 weeks of the course. Each video produced covers only one concept in depth.

Students' learning was assessed via the concept inventory for engineering thermodynamics (CIET) developed by Vigeant and colleagues. This was administered at the beginning and end of the semester (Prince - 2009, Vigeant 2009 , Vigeant 2011). The Concept Inventory is established to be a reliable measure of conceptual understanding in thermodynamics using the Kuder-Richardson Formula $20($ KR20 $=0.80)$.

Results and Discussion

Table 1 shows the post-test scores for students who both made and watched conceptual videos, along with the scores from the "control group" that neither made nor watched videos on these concepts. Both groups consist of students enrolled in 
chemical engineering thermodynamics at the three participating schools. The experimental data are from the 2013-14 academic year, and the control is from the year before the study began, in the 2010-11 academic year. Pre-test scores are similar for both the control and experimental groups (15.35 and 15.57, respectively).

Table 1: Mean Post-test scores

\begin{tabular}{|l|c|c|c|}
\hline Intervention & Mean & $\mathrm{n}$ & Standard Deviation \\
\hline No Films (Control) & 23.72 & 58 & 4.37 \\
\hline $\begin{array}{l}\text { Watched and Made } \\
\text { Films }\end{array}$ & 21.18 & 71 & 5.60 \\
\hline
\end{tabular}

No significant differences were found between the experimental and control outcomes on the CIET. Because each student group made a video for only one concept, CIET performance was further examined for correlation between concept area in the video and score on questions related to that concept. There were no clear correlations, and it should be noted that the $n$ becomes quite small at this level of analysis.

This outcome was surprising for the faculty, who observed significant perceived learning on the part of the students during video production, as well as qualitative evidence of learning in students' written reflections on the video making process. However, it is also evident that perhaps too much effort was devoted by students to making videos look and sound good. We hypothesize that the cognitive load devoted to this takes their concentration from the underlying thermodynamics. Further, in a team of 3-4 students, individuals can specialize. Observations suggest that some students concentrated nearly exclusively on video editing and acting and did not participate meaningfully in understanding the concepts. Therefore, the faculty are conducting one additional test wherein smaller student teams will be asked to make multiple, short, single illustration videos with minimal editing, effectively minimizing the barriers implicit in the current approach.

A positive and expected outcome is that the video catalog now consists of over 30 quality videos on these concepts. These videos can be used in future classes and by other instructors to introduce ideas, generate class discussion, and provide alternate explanations of these challenging ideas. While they cannot take the place of an instructor in terms of fostering conceptual understanding, they can effectively provide a foundation upon which an instructor can build.

\section{Acknowledgements}

The authors gratefully acknowledge funding support from NSF DUE TUES program \#1043697. 


\section{References}

Abulencia, J.P. Vigeant, M.A., and Silverstein, D.L., "Teaching Thermodynamics Through Video Media", Proceedings of the 2013 ASEE National Conference, (2013)

Abulencia, J.P. Vigeant, M.A., and Silverstein, D.L., "Teaching Thermodynamics Through Video Media", Proceedings of the 2014 ASEE National Conference, (2014)

Prince, Michael J., Vigeant, M., and Nottis, K., "A Preliminary Study on the Effectiveness of Inquiry-Based Activities for Addressing Misconceptions of Undergraduate Engineering Students", Education for Chemical Engineers, 4:29 (2009)

Vigeant, M., Prince, M., and Nottis, K., “Creating of Reliable Instruments for Assessment of Conceptual Understanding in Heat Transfer and Thermodynamics", AIChE Annual Meeting, 2009

Vigeant, M., Prince, M., and Nottis, K., "Fundamental Research in Engineering Education, Development of Concept Questions and Inquiry-Based Activities in Thermodynamics and Heat Transfer: An Example for Equilibrium vs Steady State", Chemical Engineering Education, 45:211 2011 